\title{
The Meaning of Biological Signals
}

Introduction to a virtual special issue on Content in Signalling Systems

Marc Artiga $^{1^{*}}$, Jonathan Birch ${ }^{2 * \dagger}$ and Manolo Martínez ${ }^{3 *}$

1: Department of Philosophy, Universitat de València, Av. Blasco Ibáñez, 30, 46010, Valencia, Spain

2: Department of Philosophy, Logic and Scientific Method, London School of Economics and Political Science, Houghton Street, London, WC2A 2AE, UK.

3: Department of Philosophy, Universitat de Barcelona, Montalegre, 6, 08001, Barcelona, Spain

* The authors (who are also the editors of the special issue) are listed in alphabetical order.

$\dagger$ Corresponding author: Jonathan Birch (j.birch2@1se.ac.uk)

This is a preprint (submitted manuscript) of an introduction that will appear in Studies in History \& Philosophy of Biological \& Biomedical Sciences. 


\begin{abstract}
:
We introduce the virtual special issue on content in signalling systems. The issue explores the uses and limits of ideas from evolutionary game theory and information theory for explaining the content of biological signals. We explain the basic idea of the Lewis-Skyrms sender-receiver framework, and we highlight three key themes of the issue: (i) the challenge of accounting for deception, misinformation and false content, (ii) the relevance of partial or total common interest to the evolution of meaningful signals, and (iii) how the sender-receiver framework relates to teleosemantics.
\end{abstract}


The concept of signalling plays an important role in many areas of the biological sciences, including behavioural ecology (Searcy and Nowicki 2005), neuroscience (Cao 2014) and cell biology (Hancock 2017). Signals convey information within biological systems and networks. They have meaning — or, as philosophers like to say, content. They represent the world as being a particular way, or they instruct the receiver to do something. The aim of the special collection is to explore the uses and limits of ideas from evolutionary game theory and information theory for explaining the content of biological signals.

For an intuitive example, consider the alarm calls of the vervet monkey (Chlorocebus pygerythrus). On observing a predator, a vervet varies its alarm call depending on whether the predator is an eagle, a leopard or a snake, allowing other nearby vervets to take the right evasive action (Cheney and Seyfarth 1990). One way of interpreting this behaviour is to say that each alarm call represents a particular state of the world: one alarm call signals that an eagle is nearby; another signals that a leopard is nearby. Many, though not all, scientists working in this area find it helpful to attribute content to the alarm calls. The calls are often described as 'semantic' or 'representational' or 'referential' or 'functionally referential' (e.g. Townsend and Manser 2013).

Recently, signalling has also become a major topic in the philosophy of science, largely due to the development of Lewis-Skyrms signalling games, also called sender-receiver models. These models were originally introduced by Lewis (1969) to study the emergence of communicative behavior, especially language. In a signalling game, a sender observes the state of a certain variable (which is drawn from a fixed probability distribution), and sends a signal, according to a strategy. The sender's strategy is a mapping (which may be probabilistic) from states to signals. A receiver then produces an act, also following a strategy, which for the receiver is a mapping 
from signals to acts (which may also be probabilistic). Each triple of state, signal and act has an associated payoff.

Skyrms' (2010) book Signals (and associated articles over many years) introduced two further innovations. First, the rational-agent perspective favored by Lewis was replaced with an evolutionary framework. The sender and receiver no longer had to be rational agents. Instead, in Skyrms's models, populations of senders and receivers evolve in accordance with simple dynamical principles, such as the replicator dynamics. This has made it possible to use senderreceiver models to model cases of signalling among non-rational agents, such as quorum sensing in bacteria (Miller \& Bassler 2001).

The second innovation was the application of information theory to the relations between states, signals and acts. It is sometimes said that information theory is a theory of quantities of information, not a theory of content. Dretske (1981) disagreed, and Skyrms (2010) revived Dretske's programme with a new way of defining the "informational content" of a signal. The contributors to this virtual special issue have a shared interest in these recent innovations, and a shared goal to investigate how they may, or may not, be used to account for the content of biological signals.

One major theme of the virtual special issue is deception, misinformation, false content, and how to account for these things within a sender-receiver framework. For example: How can a signal come to carry false content? Birch (2014) highlighted a problem for Skyrms' framework in accounting for cases in which a signal informs the receiver that $p$, when in reality $\sim p$. Skyrms \& Barrett (2019) propose a new account of the propositional content of a signal that is intended to solve this problem. They suggest, in short, that the propositional content of a signal is fixed by its uses in common-interest contexts: cases in which the sender and receiver have a shared interest 
in getting things right. When the signal is used outside these contexts, in cases where the sender and receiver have a conflict of interest, false content may arise.

Godfrey-Smith (2020) criticizes Skyrms \& Barrett's proposal, and Birch's earlier proposal, and argues that a better way to handle deception and false content is via a concept of functional content (see also Shea et al. 2018). Artiga (2020), like Godfrey-Smith, is sceptical of the prospects for any purely information-theoretic account of content. As Artiga notes, there is not just the problem of accounting for false content: there is also the problem of giving a principled account of how states of the world should be individuated - the "partition problem". For these and other reasons, he argues that the success of current models of signalling fails to vindicate an informational theory of meaning.

Meanwhile, Martínez (2019) targets Skyrms' (2010) account of deception, arguing that, in games in which sender and receiver interests are partially but not fully aligned, there can be cases, usually taken to involve deception, which can be fruitfully described as instances of cooperative "channel management". The concept of deception is also central to Birch's (2019) article. Birch considers whether there can be altruistic deception, or "white lies", among animals. He criticises definitions of "deception" in biology that make white lies impossible by definition, and then suggests an example: adult pied babblers (Turdoides bicolor) use a signal that means "food" to deceive juveniles into following them away from predators.

A second, overlapping major theme is the importance (or not) of common interest to the evolution of meaningful signals. As Skyrms \& Barrett emphasize, the ideal case for information transfer is one where the interests of senders and receivers are perfectly aligned. If their interests are totally misaligned, so that the receiver would never use information in a way beneficial to the sender, communication will never get off the ground. But what if there is partial alignment of 
interest? There is a large grey area here in which we expect some information to be transferred, but perhaps some to be withheld. These cases of partial common interest are discussed by Godfrey-Smith and modelled formally by Martínez, but the article by Rubin, Bruner, O'Connor and Huttegger (2020) looks at them in the real world —in an experimental signalling game. They find that, as predicted on theoretical grounds, we really do find partial information transfer when interests are partially aligned.

It's natural to ask how the growing literature on signalling games relates to teleosemantics, which attempts to use resources from evolutionary biology to give an account of the nature of representation, including the content of signals (Millikan 1984; Papineau 1987; Neander 2017; Shea 2018). Can the teleosemantics programme and the sender-receiver framework be unified, as some (e.g. Shea et al. 2018) have suggested? Or are there unresolved tensions between the two approaches? There is an interesting division in the virtual special issue between those authors seeking to integrate sender-receiver models with ideas from teleosemantics (like Godfrey-Smith and Artiga) and those seeking to understand signalling using game- and information-theoretic concepts without relying on ascriptions of biological function to the signals (like Skyrms \& Barrett).

The article by Bergstrom, Huttegger and Zollman (2020) falls within the second camp. Although the issue of what fixes the content of a signal has been extensively discussed, the issue of what a signal is has been comparatively neglected. The obvious move here would be to appeal to content and function, and to characterize signals as vehicles of content with the function of influencing receiver behaviour by virtue of their content. But Bergstrom et al. (2020) argue that we need not, and should not, go down this route. We can instead define a signal in nonteleological, non-functional terms, in terms of the notion of an "information-revealing" move in 
a game. Martinez (2019), furthermore, shows how sender-receiver models can be explored using tools from the branch of information theory called rate-distortion theory.

In sum, we hope that scientists and philosophers of science with an interest in the meaning of biological signals will find plenty to think about in this virtual special issue. The issue offers new accounts of propositional content and deception in simple signalling systems, new analyses of how informational and semantic content relate to each other, new insights (both theoretical and experimental) into the role of common interest in generating meaning, and explorations of what makes something a signal in the first place.

\section{References}

Artiga, M. (2020). Models, information and meaning. Studies in History \& Philosophy of Biological \& Biomedical Sciences, 82, 101284. https://doi.org/10.1016/j.shpsc.2020.101284

Bergstrom, C. T., Huttegger, S. \& Zollman, K. (2020). Signals without teleology. Studies in History \& Philosophy of Biological \& Biomedical Sciences, in press.

Birch, J. (2014). Propositional content in signalling systems. Philosophical Studies, 171, 493512.

Birch, J. (2019). Altruistic deception. Studies in History \& Philosophy of Biological \& Biomedical Sciences, 74, 27-33. https://doi.org/10.1016/j.shpsc.2019.01.004

Cao, R. (2014). Signaling in the brain: In search of functional units. Philosophy of Science, 81, 891-901. https://doi.org/10.1086/677688 
Cheney, D. L., \& Seyfarth, R. M. (1990). How monkeys see the world: Inside the mind of another species. Chicago, IL: University of Chicago Press.

Dretske, F. I. (1981). Knowledge and the flow of information. Cambridge, MA: MIT Press.

Godfrey-Smith, P. (2020). In the beginning there was information. Studies in History \& Philosophy of Biological \& Biomedical Sciences, 80, 101239.

https://doi.org/10.1016/j.shpsc.2019.101239

Hancock, J. T. (2017). Cell Signalling, 4 edition. Oxford: Oxford University Press.

Lewis, D. K. (1969). Convention: A philosophical study. Cambridge, MA: Harvard University Press.

Martínez, M. (2019). Deception as cooperation. Studies in History and Philosophy of Biological \& Biomedical Sciences, 77, 101184. https://doi.org/10.1016/j.shpsc.2019.101184

Miller, M. B. \& Bassler, B. L. (2001). Quorum sensing in bacteria. Annual Reviews in Microbiology, 55, 165-199.

Millikan, R. G. (1984), Language, Thought and Other Biological Categories. Cambridge, MA: MIT Press.

Neander, K. (2017) A Mark of the Mental: In Defense of Informational Teleosemantics. Cambridge, MA: MIT Press.

Papineau, D. (1987). Reality and Representation. Oxford: Basil Blackwell. 
Rubin, H., Bruner, J., O’Connor, C. \& Huttegger, S. (2020). Communication without common interest: A signaling experiment. Studies in History and Philosophy of Biological \& Biomedical Sciences, in press. https://doi.org/10.1016/j.shpsc.2020.101295

Searcy, W. A. \& Nowicki, S. (2005). The evolution of animal communication: Reliability and deception in signaling systems. Princeton, NJ: Princeton University Press.

Shea, N. 2018, Representation in Cognitive Science. Oxford: Oxford University Press.

Shea, N., Godfrey-Smith, P. \& Cao, R. (2018). Content in simple signalling systems. British Journal for the Philosophy of Science, 69, 1009-1035. https://doi.org/10.1093/bjps/axw036

Skyrms, B. (2010). Signals: Evolution, Learning \& Information. Oxford: Oxford University Press.

Skyrms, B. \& Barrett, J. A. (2019) Propositional content in signals. Studies in History and Philosophy of Biological and Biomedical Sciences, 74, 34-39.

Townsend, S. W., \& Manser, M. B. (2013). Functionally referential communication in mammals: The past, present and future. Ethology, 119, 1-11. 